mediate G-protein-dependent activation of adenylyl cyclase, which in turn produces the intracellular messenger, cyclic AMP (Fig. 1). Cyclic AMP depolarizes the cell by activating cation-selective cyclic-nucleotide-gated (CNG) ion channels ${ }^{2}$. These channels are highly permeable to $\mathrm{Ca}^{2+}$ (refs 3,4 ), leading to a rise in the concentration of intracellular $\mathrm{Ca}^{2+}$ which has two opposing effects: it activates a depolarizing $\mathrm{Ca}^{2+}$-dependent $\mathrm{Cl}$-conductance that amplifies the current generated by cAMP ${ }^{5}$, and it causes the cell to adapt ${ }^{3}$.

Several mechanisms by which $\mathrm{Ca}^{2+}$ can evoke an adaptive response have already been proposed, varying from inhibition of cAMP production $^{6}$ or stimulation of cAMP hydrolysis ${ }^{7}$, to $\mathrm{Ca}^{2+}$-mediated desensitization of the CNG channel'. However, receptor-protein phosphorylation has also been shown to decrease the activity of adenylyl cyclase ${ }^{9}$, and this mechanism is not dependent on $\mathrm{Ca}^{2+}$.

How can the relative importance of these putative adaptation mechanisms be determined? An advantage of working with sensory receptors is that their responses can be measured electrophysiologically, with excellent time resolution and sensitivity. Kurahashi and Menini ${ }^{1}$ first studied the effect of a pulse of odorant on the response that was evoked by a second pulse of the same odorant. They showed that the first (adapting) stimulus did indeed decrease the response to the second stimulus but, more importantly, the adapting stimulus shifted the dose-response relationship to higher concentrations of the odorant.

The authors next examined the effect of the first pulse of odorant on the current that was evoked by a subsequent pulse of cAMP (produced by photoactivation of caged cAMP). Surprisingly, the current that was evoked by the caged cAMP was reduced by the same amount as the response to the second pulse of odorant. So adaptation seems to occur after the production of cAMP, ruling out receptor-protein phosphorylation and inhibition of adenylyl cyclase as being part of the adaptation mechanism.

Kurahashi and Menini ${ }^{1}$ also showed that the decay rate of the response to odorants is affected very little by adaptation, arguing against the involvement of $\mathrm{Ca}^{2+}$-dependent stimulation of cAMP hydrolysis. So they conclude that $\mathrm{Ca}^{2+}$-mediated desensitization of the CNG channel is the dominant mechanism of olfactory adaptation (Fig. 1). This is remarkably simple - an influx of $\mathrm{Ca}^{2+}$ through the CNG channel decreases the affinity of the channel for cAMP, thereby decreasing response amplitude and sensitivity. The authors attribute the $\mathrm{Ca}^{2+}$-mediated desensitization of the $\mathrm{CNG}$ channel to the effect of calmodulin (with which $\mathrm{Ca}^{2+}$ interacts) on the channel ${ }^{8}$. However, calmodulin-independent desensitization has also been described ${ }^{10}$, and the relative importance of the calmodulin-dependent and -independent mechanisms is not yet known.

As most (if not all) odorants are detected by the cAMP pathway ${ }^{2}$, desensitization of CNG channels may be a common mechanism of adaptation for odorants. Interestingly, the vertebrate rod and cone photoreceptors also use CNG channels to generate an electrophysiological response. Moreover, adaptation of photoreceptors - like that of olfactory receptors - is triggered by the change in the intracellular concentration of $\mathrm{Ca}^{2+}$ that accompanies the response to the stimulus ${ }^{11}$, and calmodulin-dependent changes in the affinity of the CNG channel for cyclic GMP have been found in both rods ${ }^{12}$ and cones ${ }^{13}$. However, the direction of stimulus-triggered changes in the concentrations of cyclic nucleotide and $\mathrm{Ca}^{2+}$ are opposite: in olfactory receptors, the concentrations of cAMP and $\mathrm{Ca}^{2+}$ increase in response to odorants whereas, in photoreceptors, cGMP and $\mathrm{Ca}^{2+}$ decrease in response to light.

In photoreceptors, the stimulus-triggered decline in $\mathrm{Ca}^{2+}$ acts through calmodulin to restore some CNGs to the open state. The lower levels of intracellular $\mathrm{Ca}^{2+}$ also lead to the activation of guanylyl cyclase, which again results in increased opening of the CNG channels ${ }^{14}$. The open state leads to depolarization of the photoreceptors, and provides a greater output-voltage range for the response to incremental changes in illumination. But although the channel-opening effects of $\mathrm{Ca}^{2+}$ are functionally 'adaptive', neither explains the 5-20-fold decrease in amplification that occurs during exposure of photoreceptors to light ${ }^{15-17}$, and which involves a change in the gain of an early transduction intermediate ${ }^{18}$, even though this decrease is known to be caused by a decline in the concentration of $\mathrm{Ca}^{2+}$ (refs 15, $17,18)$. So Kurahashi and Menini ${ }^{1}$ have given those who study adaptation in olfactory receptors 'one up' on those tracking down the mechanisms of light-adaptation in photoreceptors - the latter are still on the hunt for the mechanism(s) that underlie a major $\mathrm{Ca}^{2+}$-dependent gain-control process.

Geoffrey $H$. Gold is at the Monell Chemical Senses Center, Philadelphia, Pennsylvania 19104-3308, USA. Edward N. Pugh Jr is in the Department of

Psychology, University of Pennsylvania,

Philadelphia, Pennsylvania 19104-6196, USA.

Kurahashi,T. \& Menini, A. Nature 385, 725-729 (1997).

. Brunet, L. J., Gold, G. H. \& Ngai, J. Neuron 17, 681-693 (1996)

3. Kurahashi, T. \& Shibuya, T. Brain Res. 515, 261-268 (1990).

4. Frings, S., Seifert, R., Godde, M. \& Kaupp, U. B. Neuron 15, 169-179 (1995)

5. Lowe, G. \& Gold, G. H. Nature 366, 283-286 (1993).

6. Sklar, P. B., Anholt, R. R. H. \& Snyder, S. H. J. Biol. Chem. 261 15538-15543 (1986)

. Borisy, F. F. et al. J. Neurosci. 12, 915-923 (1992).

8. Liu, M., Chen, T.-Y., Ahamed, B., Li, J. \& Yau, K.-W. Science 266 , 1348-1354 (1994)

9. Boekhoff, I. \& Breer, H. Proc. Natl Acad. Sci. USA 89, 471-474 :992).

10. Balasubramanian, S., Lynch, J. W. \& Barry, P. H. J. Membr. Biol. I52, 13-23 (1996).

11.Matthews, H. R., Murphy, W., Fain, G. L. \& Lamb, T. D. Nature 334, 67-69 (1988)

12. Hsu, Y.-T. \& Molday, R. S. Nature 361, 76-79 (1993).

13. Hackos, D. H. \& Korenbrot, J. I. Biophys. Soc. J. 72, A115 (1997).

14. Hodgkin, A. L. \& Nunn, B. J. J. Physiol. (Lond.) 403, 439-471 (1988).

15. Lagnado, L. \& Baylor, D. A. Nature 367, 273-277 (1994).

16. Jones, G. J. J. Physiol. (Lond.) 487, 441-451 (1995).

17. Gray-Keller, M. P. \& Detwiler, P. B. Neuron 17, 323-331 (1996)

18. Matthews, H. R. J. Gen. Physiol. 109, 141-146 (1997).

\section{Archaeology \\ Plus c'est le même chews}

This small piece of used chewing gum (actual size) is 6,500 years old. It was found in a bog at Bökeberg in Sweden, and similar ancient chewing gum has been discovered at sites all over Northern Europe. What was it made of?

It is clearly some sort of natural tar. Pine resin was one possibility - it is easily prepared, and has been used as chewing gum historically. But analysis of tar from several sites by Elizabeth Aveling at the University of Bradford points to another source: birch-bark (Br. Archaeol. no. 21, 6; 1997). Birch-bark tar was used for many other purposes at the time, including glue and waterproofing. Ötzi, the alpine 'Ice Man' found in 1991, had his axe stuck together with it, for example.

From the size of the tooth marks, the birch-bark gum was mostly chewed by children and teenagers. "Although the taste cannot be described as pleasant," Aveling writes of gum made in the lab, "neither is it

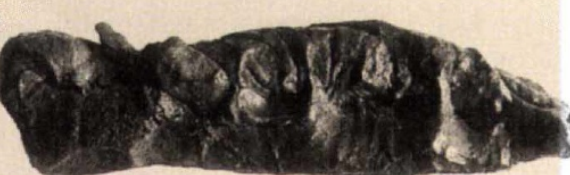

entirely unpleasant - and who knows what appealed to the mesolithic palate?" It doesn't appear to be narcotic. Did it help remove loose milk teeth or to fight plaque? Was it used as a pacifier, as a disinfectant for sore throats, or was it just chewed to disgust adults?

Some ingenuity and effort was needed to make the stuff. The bark must be heated to drive out the sap, but if it is heated in air it simply chars. Neolithic people could have used sealed jars, but ceramics are unknown before about 5,600 years ago, so how the mesolithic cultures made it is a mystery.

As for the most obvious question does your chewing gum lose its flavour underground over the millennia? - sadly no one has been allowed to taste the ancient gum to find out.

Stephen Battersby 